\title{
PENGELOLAAN STRATEGI BRANDING APPLE INC. UNTUK MENCIPTAKAN LOYALITAS KONSUMEN
}

\author{
Christian Anggrianto ${ }^{1}$, Nassiriah Shaari ${ }^{2}$, Norsiah binti Abdul Hamid ${ }^{3}$ \\ ${ }^{1}$ Universitas Ciputra \\ 2,3Universitas Utara Malaysia
}

\begin{abstract}
Abstrak: Apple sebagai merk yang terkenal dengan inovasinya, telah mampu bertahan di posisi puncak Most Valuable Brand selama bertahun-tahun. Apple Inc. telah mampu membangun dan mengelola brand sehingga dicintai oleh konsumennya dan menjadi top of mind diantara produk sejenisnya. Strategi pengelolaan merk seperti apakah yang dilakukan oleh Apple Inc.? Melalui metode penelitian dengan jenis data kualitatif melalui wawancara terstruktur kepada para responden dari kalangan praktisi sekaligus akademisi branding dan didukung dengan studi literatur ini, ditemukan bahwa Apple telah berhasil menciptakan strategi branding yang baik dengan mengidentifikasikan siapa target marketnya, dan menciptkan visi misi yang berkomitmen untuk menciptakan solusi untuk permasalah yang dihadapi oleh target marketnya, tidak berhenti sampai disitu namun Apple inc. mampu menerjemahkan visi tersebut menjadi brand strategy yang mampu menciptakan pengalaman unik dan membangun kedekatan emosional antara konsumen dengan brand, dan akhirnya tercipta loyalitas terhadap brand Apple. Hasil dari riset ini berguna untuk membantu perusahaan-perusahaan lain memahami bagaimana cara mengelola merk yang mereka miliki hingga bisa memperoleh loyalitas dari konsumennya.
\end{abstract}

Keyword: consumer insight, emotional branding, brand communication, brand experience, brand loyalty.

Abstract: Apple as a brand which is well-known for its innovation, has been able to remain at the top of Most Valuable Brand for years. Apple Inc. has successfully built and managed its brand that is consequently esteemed by its customers and becomes 'top of mind' among the similar products. What kinds of brand management strategies has Apple Inc. organized? Through a research method of qualitative data with structured interviews to several respondents from practitioners, branding academicians, and being supported by literature study, it is found that Apple has effectively designed an excellent branding strategy by identifying its target market, and constructing its vision and mission that commit to invent solutions to the problems faced by its target market. Furthermore, Apple inc, is able to interpret the vision to become a brand strategy that affords to create unique experiences and build emotional approach between the brand and its customers which consequently develop the brand loyalty. The research finding is valuable for facilitating other companies to manage their brands in order to gain their customers' loyalty.

${ }^{1}$ Universitas Ciputra, email: christ.ang@ciputra.ac.id

2Universitas Utara Malaysia, email: nasiriah@uum.edu.my

3Universitas Utara Malaysia, email: nor1911@uum.edu.my 
Keyword: consumer insight, emotional branding, brand communication, brand experience, brand loyalty.

\section{PENDAHULUAN}

Memiliki sebuah merk yang menjadi favorit dan diterima oleh pasar merupakan harapan dari semua perusahaan, apalagi bila merk tersebut menjadi Top of Mind di kelasnya. Namun untuk menjadi favorit dan top of mind merupakan hal yang sulit sekali untuk dicapai, banyak merk-merk yang bermunculan tapi tidak banyak yang bisa bertahan dan mencapai tahapan tersebut. Salah satu merk yang berhasil mencapai hal tersebut adalah Apple Inc.

\section{BrandZ ${ }^{\text {TM }}$ Top 100 Most Valuable Global Brands 2017}

\begin{tabular}{|c|c|c|c|c|c|c|}
\hline & Brand & Category & $\begin{array}{l}\text { Brand Value } \\
2017 \text { S:Mili. }\end{array}$ & $\begin{array}{l}\text { Brand } \\
\text { Contribution }\end{array}$ & $\begin{array}{l}\text { Brand value } \\
\times \text { change } \\
2017 \text { va. } 2016\end{array}$ & $\begin{array}{r}\text { Pank } \\
\text { Change }\end{array}$ \\
\hline 1 & Google & Technology & 245,581 & 4 & $7 \%$ & 0 \\
\hline 2 & & Technology & 234,671 & 4 & $3 \%$ & 0 \\
\hline 3 & - Microsoft & Technology & 143.222 & 4 & $18 x$ & $\circ$ \\
\hline 4 & amazon & Rotail & 139.286 & 4 & AIs: & 3 \\
\hline 5 & facebook & Technology & 129800 & 4 & $27 x$ & 0 \\
\hline 6 & AT\&T & Telecom Providers & $115, \pi 2$ & 3 & $7 \%$ & -2 \\
\hline 7 & ISA & Payments & no.999 & 4 & $10 x$ & -1 \\
\hline 8 & Tencent 䠐讯 & Technology & 108.292 & 5 & $27 \%$ & 3 \\
\hline 9 & 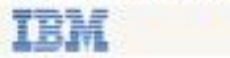 & Technology & 102008 & 4 & $18 \%$ & 1 \\
\hline 10 & McDonald's & Fast Food & 97,723 & 4 & $10 \%$ & -1 \\
\hline
\end{tabular}

Gambar 1. Top 100 Most Valueable Global Brand 2015 by BRANDZ Sumber: www.brandz.com

Dari hasil riset tahunan Most Value Global Brand 2016 yang dilakukan oleh BRANDZ, sebuah bank data brand equity terbesar dunia, Apple Inc. menduduki posisi kedua dalam kategori teknologi dengan nilai sebesar 
\$234.671.000 di tahun 2017 (gambar 1), mengalahkan AT\&T di nomer 6, bahkan Samsung yang selama ini dianggap sebagai pesaing utamanya hanya menduduki peringkat 37. Hal ini membuktikan pernyataan yang disampaikan oleh Wheeler (2013) bahwa untuk bisa bertahan dalam persaingan sebuah perusahaan perlu strategi branding yang baik, karena persaingan dewasa ini adalah kompetisi antar brand (Robert, 2013).

Semua produk dari Apple inc. selalu berhasil menarik perhatian para konsumennya, sebagai contoh beberapa saat setelah Tim Cook, CEO dari Apple Inc. menyampaikan bahwa produk terbarunya yaitu Apple Watch akan segera tersedia di pasar mulai tanggal 24 April 2014 (gambar 2), antusiasme pasar melonjak, Apple watch merupakan piranti hibrida yang menghadirkan fungsifungsi yang mampu memudahkan penggunanya dalam aktifitas kesehariannya dalam sebuah jam tangan, dimana sebelumnya mungkin dibutuhkan beberapa piranti berbeda namun sekarang cukup dengan satu buah smart watch.

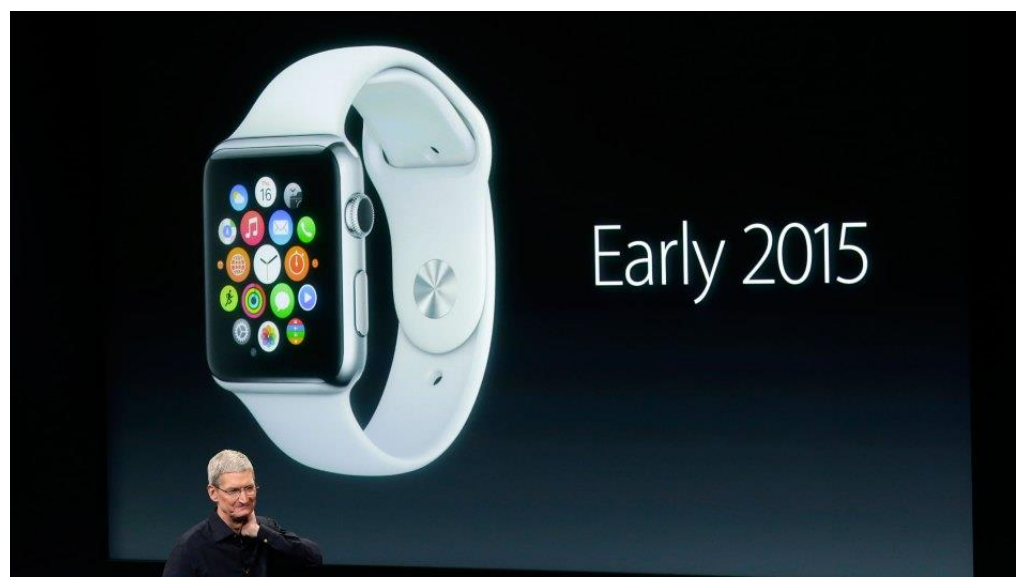

Gambar 2. CEO Apple Inc Tim Cook mempresentasikan Apple Watch Sumber: www.idownloadblog.com

Antusiasme ini nampaknya tidak hanya terjadi di kalangan konsumen, namun juga di produsen. Banyak perusahaan atau brand lain yang mulai menyadari potensi pasar dari kategori smart watch ini, dan mulai memikirkan untuk masuk ke dalam peta persaingan produk ini. Tak lama setelah presentasi 
Tim Cook, bahkan sebelum Apple Watch tersedia di pasaran, produsen-produsen China sudah mulai menawarkan produk serupa melalui situs belanja online, produk-produk tersebut memiliki tampilan fisik serta feature yang mirip Apple watch dengan harga jual yang sangat murah bila dibandingkan dengan produk aslinya (gambar 2). China merupakan negara yang terkenal dengan kemampuannya untuk mengkopi dan menciptakan produk dengan biaya lebih rendah.

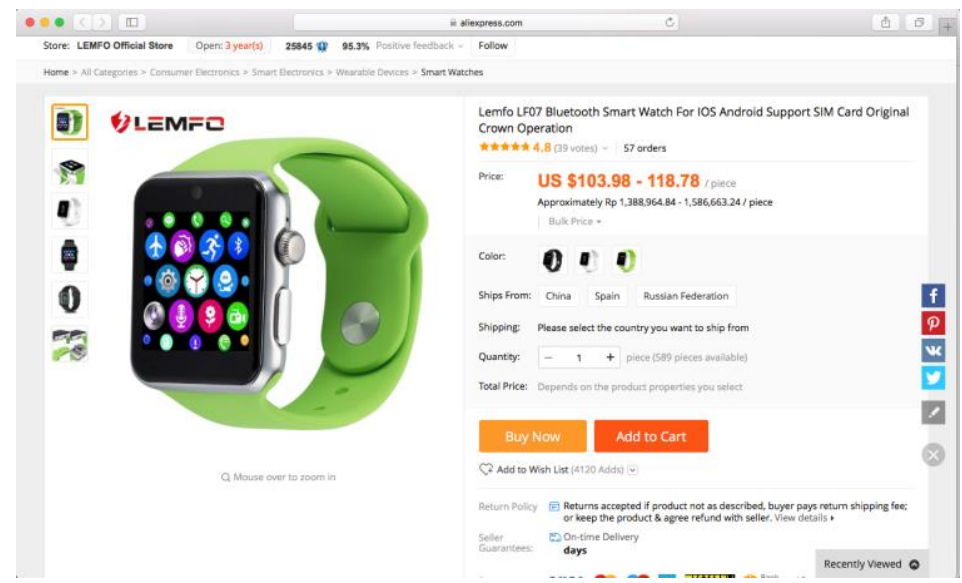

Gambar 2. Contoh salah satu versi Imitasi Apple Watch dari China Sumber: www.aliexpress.com

Namun ternyata keberadaan produk-produk imitasi yang lebih mudah didapat, memiliki feature yang mirip dan memiliki harga lebih murah ini, tidak mengurangi antusiasme dari pasar untuk memiliki produk terbaru dari Apple Inc., para

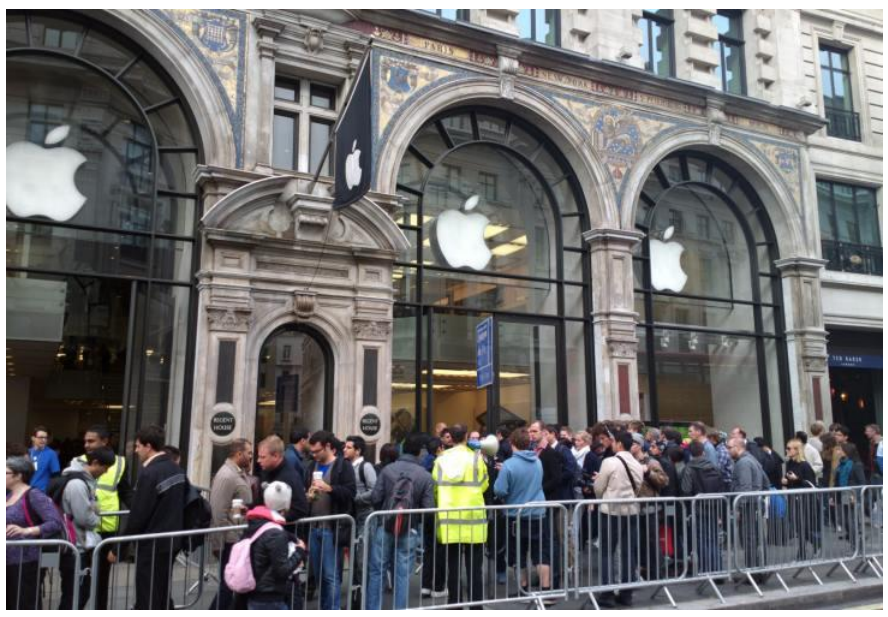

Gambar 3. Antrian di depan Apple Store Sumber: www.product-reviews.net 
konsumen tetap rela mengantri hingga berkemah di depan Apple Store (gambar 3) demi menjadi orang pertama yang memiliki produk baru Apple.

\section{TUJUAN PENELITIAN}

Penelitian ini bertujuan untuk mengetahui strategi branding seperti apa yang dipergunakan oleh Apple Inc. sehingga mampu bertahan menjadi Top of Mind di benak konsumennya. Hasil penelitian ini diharapkan dapat berkontribusi dalam membangun wacana mengenai pentingnya pengelolaan brand untuk meningkatkan nilai Jual dan daya saing sebuah bisnis.

\section{METODE PENELITIAN}

Penelitian ini menggunakan metode penelitian dengan jenis data kualitatif yang didukung dengan studi literatur. Metode pengumpulan data akan menggunakan wawancara terstruktur kepada bapak Jacky Cahyadi dari Action Frame Design, Niko Pranoto dari Cocinero Design, serta Marvin dari Google Business Group coach, para responden ini dipilih karena mereka berprofesi baik sebagai praktisi sekaligus akademisi branding. Tiap orang responden ini akan diwawancara mengenai pemahaman dan pengalaman mereka dalam strategi pengembangan merk.

\section{KAJIAN TEORI DAN WAWANCARA}

Menurut Asosiasi Marketing Amerika, dalam buku The Power of Brands, brand (merek) adalah nama, istilah, simbol atau rancangan atau kombinasi dari hal-hal tersebut. (Rangkuti, 2002: 1-2) Sementara dalam buku Brand Operation, merek berfungsi untuk mengidentifikasi produk atau jasa yang ditawarkan perusahaan dan membedakannya dari pesaing. Sementara branding adalah rangkaian kegiatan komunikasi perusahaan dalam proses membangun, 
membesarkan, dan memperkuat brand di benak konsumen (Handayani, dkk, 2010: 60).

Sakti Makki, pendiri dari Makkimakki sebuah strategic branding consultant ternama di Indonesia, menyatakan brand akan menjadi tidak berguna dan tidak berharga bila tidak memiliki Audience atau orang yang menyaksikan, oleh karena itu hal terpenting yang harus dilakukan dalam membangun brand adalah menemukan penontonnya, apa yang muncul di benak penonton ketika mereka melihat merk atau dikenal dengan istilah consumer insight.

Untuk membangun program komunikasi yang efektif, aspek yang harus diperhatikan adalah memahami proses yang dilalui konsumen dalam memutuskan untuk membeli suatu produk. Dalam buku Marketing, ada 4 tahap yang dilalui konsumen dalam menentukan keputusan pembelian yang dikenal dengan model AIDA. (Lamb, dkk., 2012: 418)

1. Attention, yaitu tahap dimana konsumen mengetahui suatu produk

2. Interest, yaitu muncul ketertarikan terhadap produk yang ditawarkan.

3. Desire, yaitu keinginan untuk memiliki produk tersebut.

4. Action, yaitu tahap dimana konsumen memutuskan untuk menggunakan produk.

Untuk merk yang berada di tahapan awal atau tahapan building, dan belum banyak dikenal konsumen harus memfokuskan aktifitasnya pada membangun kesadaran. Kesadaran adalah tingkat pengenalan dan kesadaran masyarakat umum terhadap produk yang diluncurkan. (Ibrahim, 2004: 68-69). Kesadaran ini lebih mengacu kepada sifat psikologis manusia, karena kesadaran ini sifatnya tidak langsung.

Untuk dapat menyampaikan nilai lebih yang mampu melekat di benak konsumen, merk harus menciptakan strategi komunikasi yang efektif untuk menjangkau konsumennya (brand communication). Seringkali merk dipersonifikasikan dengan sifat serta karakter yang manusiawi (personification) 
sehingga konsumen dapat lebih mudah berelasi dengan merk tersebut secara emosional atau sering disebut emotional branding. (Cahyadi, Jacky. "Brand Process". 24 Agustus 2016. wawancara)

Kesadaran sangatlah penting dalam upaya memasukkan sugesti ke benak konsumen disaat mereka memikirkan dan memilih sebuah produk. Pada tahap ini, kegiatan yang dilakukan bertujuan menarik perhatian (attention) dan mengenalkan merk kepada konsumen agar mereka sadar akan eksistensi merk.

Perusahaan-perusahaan sendiri berusaha membangun kesadaran akan merk konsumen produk mereka, dengan tujuan mencapai top of mind konsumen dalam memikirkan sebuah kategori produk, contoh : minuman berkarbonasi, yang pertama muncul di benak adalah Coca Cola. Kesadaran akan merk masing-masing konsumen dapat berbeda-beda tergantung tingkat kesadaran yang dicapai mereka.

Kemudian setelah merk dikenal, dilanjutkan dengan image building yang bertujuan untuk membuat konsumen paham mengenai keunggulan merk dan produk yang melekat didalamnya (interest).

Untuk menjadi merk yang baik dan mampu bertahan di tengah persaingan pasar maka sebuah merk tidak boleh hanya mengandalkan produknya, melainkan harus mampu memberikan pengalaman yang unik dan berbeda terhadap customernya, yang dikenal dengan istilah Brand Experience (Pranoto, Niko. "Branding and corporate identity". 27 Maret 2017. Wawancara). Pengalaman terhadap merk itu sendiri merupakan pengalaman pribadi yang didapatkan konsumen terhadap sebuah produk yang dihasilkan dari kegiatan membeli, penggunaan produk, pelayanan, dan sebagainya. Brand experience sendiri juga sangat penting, terutama juga berpengaruh dalam mencapai top of mind konsumen.

Pengalaman terhadap merk mempengaruhi kesetiaan konsumen. Berbagai penelitian membuktikan bahwa pelanggan yang terlibat dengan merk di ruang 
digital - walaupun hanya sekedar 'liking' sebuah merk di facebook - memiliki kecenderungan untuk bukan hanya membeli produk tersebut tetapi juga membuat rekomendasi tentang produk tersebut ke teman dan keluarga. (Google Business Group. “Brand Former”. 25-26 Juni 2016, Personal Interview)

Setelah brand dikenal dan dipahami konsumen, maka langkah berikutnya adalah meningkatkan minat konsumen agar mencoba dan membeli produk yang ada hingga konsumen menjadi setia terhadap merk yang dibangun (desire). Produk hanyalah sebuah sarana untuk menyampaikan pengalaman unik tersebut kepada konsumen, oleh karena itu pengalaman unik yang ditawarkan haruslah khas dan tidak dimiliki oleh brand lain, dan tidak hanya sekedar memberikan pembeda bahwa merk tersebut lebih cepat, lebih murah, lebih sederhana, lebih sederhana (Mitra, Startupbisnis.com, 2014)

Oleh karena itu membangun merk berarti membangun sebuah aktivitas yang terencana dan membutuhkan desain kreatif yang dilakukan secara berkelanjutan. Dalam membangun aktivitas brand yang baik, diperlukan analisis awal untuk menilai dan mengukur tingkat pencapaian brand saat ini, apakah brand berada di tahap dikenal, dipahami, disukai, dicintai, ataukah di titik loyal.

Selain itu perlu dipahami bahwa kebutuhan tiap manusia berbeda, berdasarkan piramida kebutuhan dari Maslow, diketahui bahwa manusia memiliki 5 kebutuhan dasar yang dibedakan menjadi 3 kategori:

1. Kebutuhan dasar:

a. Kebutuhan fisiologis, yakni kebutuhan untuk mempertahankan hidupnya secara fisik. Seperti: makanan, minuman, tidur, dll.

b. Kebutuhan akan rasa aman, yakni kebutuhan akan rasa aman fisik, stabilitas, kesehatan, perlindunga dari ancaman, dll.

2. Kebutuhan psikologis:

a. Kebutuhan kasih sayang, yakni kebutuhan untuk diterima, persahabatan, keintiman, dan hubungan. 
b. Kebutuhan penghargaan, yakni kebutuhan untuk mendapatkan pengakuan, dihargai, dihormati, diperhatikan, harga diri, dll. Dengan terpenuhinya kebutuhan in maka manusia akan mampu memasuki gerbang aktualisasi diri.

3. Kebutuhan untuk aktualisasi diri: yakni kebutuhan untuk pemenuhan diri, memenuhi potensi diri, dan menjadi apapun sesuai dengan kemampuannya.

\section{HASIL DAN DISKUSI}

Dari hasil riset yang dilakukan oleh research-methodology.net diketahui bahwa segmentasi dari pengguna Apple adalah para professional, eksekutif dan pelajar dari kalangan menengah keatas, lebih khususnya mereka yang menginginkan pelayanan yang cepat dan mudah, ingin tampil keren dan beda, mencoba hal yang baru, serta percaya diri, selain itu mereka juga merupakan orang-orang yang tahu apa yang mereka kehendaki dan ambisius. (Dudovskiy, Research-Methodology.net, 2017),

Berdasarkan piramida Maslow profil pengguna dari Apple adalah orang orang yang memiliki kebutuhan akan self actualization, esteem serta Belonging and love, oleh karena itu Apple menciptakan pendekatan-pendekatan yang dapat memuaskan kebutuhan sekaligus menciptakan sebuah positioning sebagai brand premium. Dengan positioning yang seperti itu secara tidak langsung Apple ingin mengatakan bahwa hanya orang-orang tertentu yang bisa memiliki produknya, hal ini otomatis menimbulkan kebanggaan tersendiri, membangun rasa percaya diri (esteem) dari para penggunanya.

Sejak awal berdiri di tahun 1977 Apple Inc.memiliki 3 Filosofi, yang digunakan sebagai pegangan mereka untuk bertindak hingga sekarang, yaitu:

1. Empathy: berusaha mengerti kebutuhan customer lebih baik dari perusahaan lain. 
2. Focus: Agar dapat berhasil maka harus fokus terhadap hal-hal yang akan dilakukan dan melepas hal-hal lainnya.

3. Impute: Masyarakat tetap akan menilai buku berdasakan sampulnya, meski memiliki produk dengan kualitas terbaik, software yang paling berguna, tapi memiliki tampilan yang buruk pasti akan dinilai dengan buruk, namun bila direpresentasikan dengan kreatif dan professional pasti akan diterima dengan baik.

Oleh karena itu Apple Inc. menjadikan customer sebagai poin utama dalam pengambilan keputusan, oleh karena itu mereka membangun tim yang mampu berempati dan melihat dari perspektif konsumen, Steve Job sebagai pendiri Apple inc. menuntut agar semua produk yang dibuat harus mengutamakan pada antarmuka dan pengalaman yg memudahkan pengguna, oleh karena itu selalu dilakukan pengetesan kebergunaan atau participatory design untuk bisa lebih memahami kebutuhan dan kesulitan yang dialami mereka. Itulah yang menyebabkan kenapa Apple mempergunakan "i" atau "saya" secara konsisten pada tiap produknya seperti iPhone, iPad, iMac untuk menciptakan personalisasi dari pemilik, dan juga berfungsi untuk memudahkan membedakan produk Apple dengan yang lain dan membuat orang mengenal keunikan merk Apple Inc. (Attention).

Daripada menekankan pada invensi Apple memilih untuk berinovasi, dengan cara menemukan cara yang lebih baik untuk melakukan sesuatu contohnya iPod merupakan innovasi dari Mp3 Player, iPhone adalah inovasi dari telepon selular, begitu juga dengan iPad, sebagaimana disampaikan oleh Jonathan Iye salah seorang Desainer dari Apple bahwa sasaran dari Apple sebenarnya sangat sederhana, yaitu mendesain dan membuat produk lebih baik. Apple ingin memposisikan dirinya sebagai merk yang mengerti keinginan konsumennya dan berusaha menciptakan kemudahan-kemudahan untuk membuat hidup mereka lebih mudah. Ini yang membedakan Apple dengan kompetitornya. 
Selain itu agar para konsumen dapat memperoleh pengalaman yang tepat dan berinteraksi langsung dengan produk-produk Apple pada umumnya dan merk Apple pada khususnya maka Apple Inc. mendirikan gerai yang dinamai Apple Store. Para konsumen dan calon konsumen bisa mencoba langsung dan merasakan kemudahan yang ditawarkan, dengan begitu rasa ingin tahu mereka bisa terjawab dan timbul keinginan untuk memiliki produk tersebut (interest dan desire)

Karena Behavioural dari konsumen apple adalah orang-orang yang mengedepankan kecepatan layanan dan efisien (Dudovskiy, ResearchMethodology.net, 2017), Apple juga menyediakan tenaga penjualan yang dilatih secara khusus untuk bisa membantu para pengunjung memperoleh pengalaman dalam berinteraksi secara maksimal dengan produk Apple, tenaga penjualan ini tidak hanya bertugas menjual tetapi juga harus memiliki pengetahuan tentang produk dengan baik bahkan mampu memberikan rekomendasi untuk menyelesaikan problem-problem teknis yang dialami oleh konsumen terhadap suatu produk melalui Genius Bar yang ada di setiap Apple Store, sehingga para konsumen bisa merasa terbantu dan dimengerti (belonging and love) kesemua pengalaman inilah yang akhirnya secara tidak langsung mendorong calon konsumen untuk memutuskan membeli produk Apple inc. (action) . Selain merancang untuk memberikan pengalaman fisik terhadap para konsumen serta calon konsumennya melalui Apple Store, Apple juga menyediakan sebuah media elektronik bernama iTunes, disana mereka bisa mencari aplikasi, berlangganan video, berita, serta musik sesuai dengan selera mereka, iTunes ini secara tidak sadar juga telah merubah habit masyarakat tentang industri musik, pengguna bisa membeli dan mendownload music favoritnya dimanapun secara legal tanpa harus ke toko musik, dan bisa membeli musik secara satuan tanpa harus membeli seluruh album seperti sebelumnya. Dengan begitu tiap pengguna 
bisa bereksplorasi dan mempersonalisasi produk dari Apple yang dimiliki sesuai dengan keinginan serta karakter pribadinya (self actualization).

\section{KESIMPULAN}

Untuk bisa mengembangkan brand yang dicintai oleh konsumennya maka perusahaan harus mampu mengenal siapa konsumennya dan mengetahui masalah apa yang dialami oleh mereka, kemudian dari situ dapat diciptakan sebuah solusi untuk problem yang dialami oleh konsumen tersebut.

Namun, sebaik apapun nilai baru itu menjawab permasalahan tetapi tidak diikuti strategi komunikasi yang baik maka semuanya akan sia-sia. Perusahaan harus mampu menciptakan sebuah medium dimana konsumen bisa berinteraksi dengan nilai tersebut dan memiliki pengalaman yang berkesan bagi mereka, untuk menjamin pengalaman itu bisa dirasakan secara maksimal maka medium tersebut harus dilengkapi dengan atribut-atribut lain seperti staf yang siap membantu, lingkungan yang ditata sedemikian rupa sehingga mampu menciptakan suasana yang mendukung pesan dan pengalaman yang ingin disampaikan.

Dan yang terpenting adalah komitmen serta konsistensi perusahaan untuk melakukan perbaikan berkelanjutan, perlu diciptakan system yang memungkinkan perusahaan untuk memperoleh masukan-masukan dari konsumen serta karyawan di lapangan sehingga perusahaan mampu melakukan perbaikan dan menyusun strategi serta pendekatan baru untuk tetap menjadi brand yang dicintai konsumennya.

\section{DAFTAR PUSTAKA}

Benson, N., Ginsburg, J., Grand, V., Lazyan, M., Weeks., M, Collin, C., 2012. The Psychology Book: Big Ideas Simply Explained. London:DK Dudovskiy, John. 2017. Apple Segmentation, Targeting and Positioning. [online] Available at: Http://Research-Methodology.net/, 6 Mar. 2017, research- 
methodology.net/apple-segmentation-targeting-and-positioning/. [Diakses 21 Juni 2017].

Handayani, D., dkk. 2010. The Official MIM Academy Coursebook Brand Operation. Jakarta: Erlangga.

Ibrahim, Darwis. 2004. SMART SELLING "Fish Where the Fish Are" Pendekatan Baru untuk Meningkatkan Penjualan. Jakarta: Elex Media Komputindo. Lamb, C.W., dkk. 2012. Marketing. USA: Nelson Education.

Landa, Robin. 2006. Designing Brand Experiences. United States of America: Thomson Delmar Learning.

Mitra, Wyndo. 2014. Sakti Makki Membagikan Resep Sukses Dalam Membangun Brand Agar Dikenal Oleh Banyak Orang. [online] Available at: Http:// startupbisnis.com/sakti-makki-membagikan-resep-sukses-dalammembangun-brand-agar-dikenal-oleh-banyak-orang/. [Diakses14 Juni 2017].

Rangkuti, Freddy. 2002. Creating Effective Marketing Plan Teknik Membuat Marketing Plan Berdasarkan Costumer Values; Analisis Kasus. Jakarta: Gramedia Pustaka Utama.

Rangkuti, Freddy. 2002. The Power of Brands: Teknik mengelola brand equity dan Strategi Pengembangan Merek + Analisis Kasus dengan SPSS. Jakarta: Gramedia Pustaka Utama. 